\title{
Clinical and Paraclinical Profile of Patients in First Nephrology Consultation at the Aristide Le Dantec University Hospital Center (ALD-UHC) About 542 Cases
}

\author{
Faye Mo*, Ait Allah I, Lemrabott AT, Faye M, Cisse MM, Fall K, Mbengue M, Keita RIA, Diouf B and Ka EF
}

Department of nephrology, Aristide Le Dantec University Hospital, Cheikh Anta Diop University, Dakar, Senegal

${ }^{*}$ Corresponding author: Faye Mo, MD, Department of nephrology, Aristide Le Dantec University Hospital, Cheikh Anta Diop University, 30 avenue Pasteur BP: 3001, Dakar, Senegal, West Africa, Tel: +33619482896; +221776656568, E-mail: mfayeintaida@gmail.com

Citation: Faye Mo, Ait Allah I, Lemrabott AT, Faye M, Cisse MM, et al. (2018) Clinical and Paraclinical Profile of Patients in First Nephrology Consultation at the Aristide Le Dantec University Hospital Center (ALD-UHC) About 542 Cases. J Nephrol Kidney Dis 1(1): 101. doi: 10.15744/2767-9225.1.101

Received Date: August 09, 2018 Accepted Date: April 27, 2020 Published Date: April 29, 2020

\begin{abstract}
Introduction: Late recourse to nephrology consultation remains a topical issue which concerns both developed and developing countries such that a majority of the patients are seen to be at an advanced stage of chronic kidney diseases. The aim of this study is to assess the clinical and paraclinical profile of patients referred for primary nephrological consultation.

Patients and methods: This is a retrospective and descriptive analysis of the medical records of the patients admitted for primary consultation at the outpatient department of the nephrology department of the Aristide Le Dantec University Hospital Center from January 1 to December 31, 2015 The data collected are the referent's specialty, the reason for consultation, and the sociodemographic, clinical, and paraclinical characteristics of the patients.
\end{abstract}

Results: In 2015, 542 new patients were admitted for outpatient nephrology. The mean age was $53 \pm 16$ years and the sex-ratio (M/F) was 1.15 . Patients were referred by a general practitioner in $51.1 \%$ of the cases. The main reason for consultation was impaired renal function in $70.1 \%$ of cases. The physical examination revealed a hypertension in $70.1 \%$ of the cases, a edema in $21.2 \%$ of which $13.0 \%$ $(\mathrm{n}=15 / 115)$ were in the anasarca state. Mean serum creatinine was $45.81 \pm 1.51 \mathrm{mg} / \mathrm{l}$. The mean glomerular filtration rate was 42.33 $\pm 35.22 \mathrm{ml} / \mathrm{min} / 1.73 \mathrm{~m} 2$. Proteinuria was noted in $69.63 \%$, microscopic hematuria in $29.41 \%$, and leukocyturia in $26.96 \%$ of the cases. Kidney ultrasound was conducted for 423 patients and $32.38 \%$ were found to have small kidneys and poor differentiation. The diagnosis was an acute kidney injury in $7.74 \%$ of the cases and a chronic renal failure in $64.02 \%$ of the cases, the majority of whom were at stage 5 of CKD.

Conclusion: Patients referred for nephrology consultation are often found to be at an advanced stage of CKD. This delayed diagnosis is associated with an increase in morbidity and mortality factors and thus a poor prognosis. For example, programs for early detection and prevention of kidney diseases should be introduced.

Keywords: First Consultation; Chronic Kidney Disease; Nephrology; Dakar

\section{Introduction}

Chronic kidney disease (CKD) is a public health problem worldwide because of its increasing frequency, severity, and high cost of management $[1,2]$. The late discovery of CKD is partly related to its asymptomatic nature, lack of training of practitioners, and lack of awareness of the population. In patients with $\mathrm{CKD}$, the earlier the nephrologist is consulted (before starting renal replacement therapy) the lower the morbidity and mortality due to better preparation for renal replacement therapy, the management of the complications of CKD such as anemia and malnutrition as well as the introduction of a conservative treatment. CKD is still often discovered at a late stage even in developed countries. In Canada, 52\% of CKD cases are in stage IV at the first nephrology consultation [3]. In sub-Saharan Africa, more than two-thirds of CKD cases are encountered for the first time at stage V [4]. Primary prevention seems to be the best way to reduce the incidence of CKD in developing countries such as Senegal. It is in this context that we undertook this work with the aims of describing the epidemiological, clinical, and paraclinical profile of the patients referred to their first nephrology consultation. 


\section{Patients and Methods}

\section{Type and Scope of Study}

This was a descriptive retrospective study conducted from January 1 to December 31, 2015. It was conducted in the outpatient nephrology department of the Aristide Le Dantec University Hospital Center (ALD-UHC) in Dakar, Senegal.

\section{Study population}

The target population was that of patients consulting in the nephrology department during the study period. Those included were patients who were visiting the ALD-UHC Nephrology Department for the first time. Patients referred directly to the hospital unit of this nephrology department, kidney transplant patients and those whose records were unusable were not included.

\section{Data collection}

Sociodemographic, clinical and paraclinical data, the specialty of the medical correspondent, and the reason for consultation were collected through manual analysis of patient files using a pre-established operating file.

\section{Definitions of Operational Variables}

Hypertension was defined as systolic and/or diastolic blood pressure greater than or equal to $140 \mathrm{mmHg}$ and $90 \mathrm{mmHg}$, respectively, and grades were determined according to the WHO 1999 Classification [5]. Glomerular filtration rate (GFR) was estimated by the Modification of Diet in Renal Disease (MDRD) formula [6]. Diabetes mellitus was retained in the presence of fasting glucose levels greater than $1.26 \mathrm{~g} / \mathrm{l}(7,1 \mathrm{mmol} / \mathrm{l})$ and/or antidiabetic therapy (oral antidiabetic agent, insulin) [7]. Other biological abnormalities were defined according to laboratory standards. The uremic syndrome was considered acute if its duration of evolution was less than 3 months.

\section{Statistical Analysis}

The data was captured by the Sphinx software version 5.1.0.2 and analyzed by Statistical Package for Social Science (SPSS) software version 18. The qualitative variables were presented in proportion (percentage). Quantitative variables were presented as mean \pm standard deviations.

\section{Results}

Of the 998 patients in the nephrology department, 690 (69.13\%) patients were admitted for consultation including 542 who were included in the study. The mean age of the patients was $53 \pm 16$ years with a sex ratio of 1.15 , and $41.50 \%$ of them came from suburban areas. The majority of the patients $(80.81 \%)$ were referred by doctors and most of them by a general practitioner. The distribution of patients according to the referent's specialty is shown in (Table 1). Renal impairment, reported in 380 patients (70.1\%), was the most frequent reason for consultation. The reasons for consultation are shown in (Figure 1). The different patient histories are shown in (Table 2).

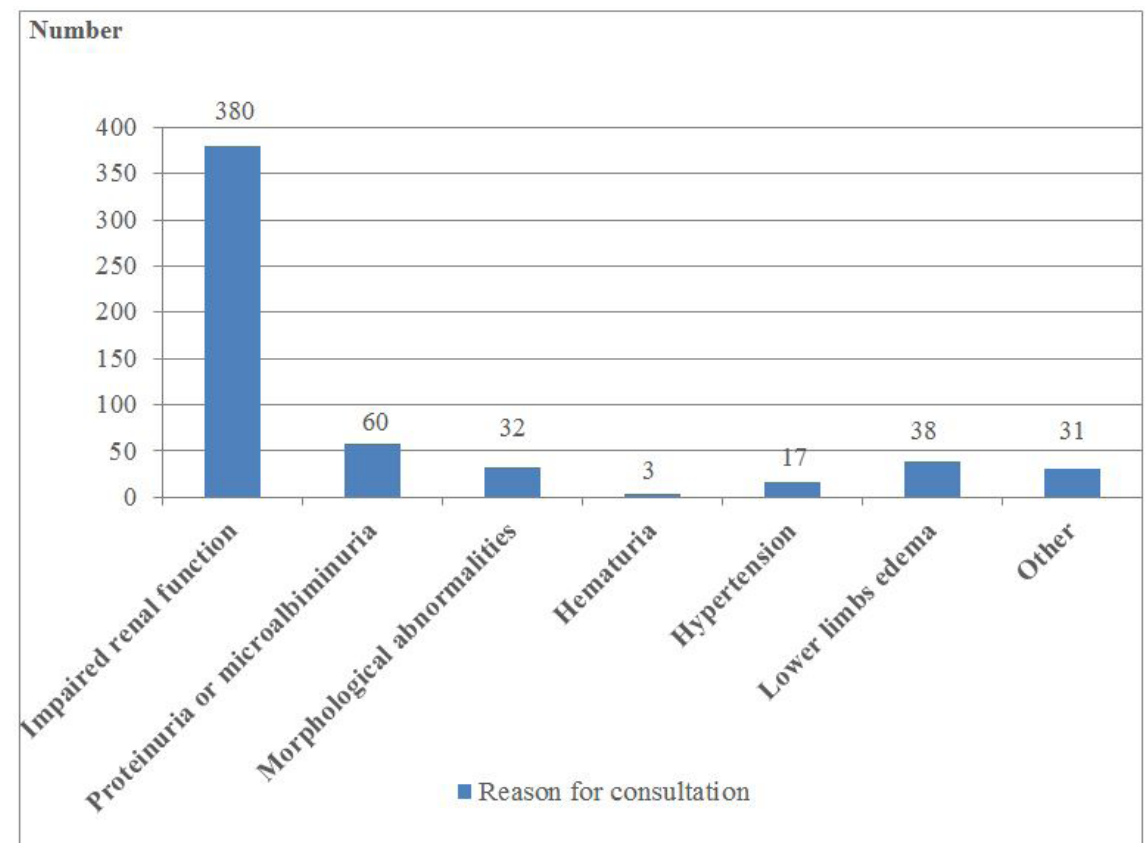

Figure 1: Distribution of 542 patients admitted first nephrology consultation according to the reason for consultation 


\begin{tabular}{|c|c|c|}
\hline Medical specialty & Number (n) & Percentage (\%) \\
\hline General practitioner & 277 & 51.11 \\
\hline Cardiology & 53 & 9.78 \\
\hline Urology & 20 & 3.69 \\
\hline Internal medicine & 19 & 3.51 \\
\hline Gynecology & 13 & 2.40 \\
\hline Dermatology & 11 & 2.03 \\
\hline Endocrinology & 11 & 2.03 \\
\hline Haematology & 11 & 2.03 \\
\hline Neurology & 10 & 1.85 \\
\hline Occupational Medicine & 10 & 1.85 \\
\hline Nephrology & 9 & 1.66 \\
\hline Rhumatology & 8 & 1.48 \\
\hline Gastroenterology & 6 & 1.11 \\
\hline Oncology & 5 & 0.92 \\
\hline Geriatrics & 3 & 0.55 \\
\hline Pulmonary medicine & 3 & 0.55 \\
\hline Infectious diseases & 3 & 0.55 \\
\hline Psychiatry & 2 & 0.37 \\
\hline Resuscitation & 2 & 0.37 \\
\hline Orthopedics & 2 & 0.37 \\
\hline Neurosurgery & 1 & 0.18 \\
\hline State nurse & 5 & 0.92 \\
\hline Traditional practitioner & 1 & 0.18 \\
\hline Unspecified & 57 & 10.50 \\
\hline Totally & 542 & 100 \\
\hline
\end{tabular}

Table 1: Distribution of 542 patients admitted in first nephrology consultation according to the referent's specialty.

\begin{tabular}{|c|c|c|}
\hline Histories & Number & Proportion (\%) \\
\hline Hypertension & 335 & 61.80 \\
\hline Diabetes mellitus & 96 & 17.70 \\
\hline Phytotherapy & 122 & 22.5 \\
\hline Anti-inflammatory agents, non-steroidal & 6 & 1.10 \\
\hline Smoking & 28 & 5.20 \\
\hline Heart diseases & 17 & 3.14 \\
\hline Gout & 9 & 1.66 \\
\hline Pulmonary tuberculosis & 6 & 1.10 \\
\hline Lupus erythematosus & 7 & 1.29 \\
\hline HIV & 3 & 0.55 \\
\hline Kidney disease & 17 & \multirow{4}{*}{3.14} \\
\hline Edema & 9 & \\
\hline Hematuria & 6 & \\
\hline Polycystic kidney diseases & 2 & \\
\hline Gynecological & 20 & \multirow{3}{*}{3.69} \\
\hline Pre-eclampsia & 15 & \\
\hline Postpartum period, AKI & 5 & \\
\hline Urologic diseases & 37 & 6.82 \\
\hline
\end{tabular}




\begin{tabular}{|c|c|c|}
\hline Histories & Number & Proportion (\%) \\
\hline Sickle Cell diseases & $\mathbf{1 5}$ & \multirow{2}{*}{2.76} \\
\cline { 1 - 2 } Hemoglobin SS disease & 9 & \multirow{2}{*}{2.10} \\
\hline Hemoglobin AS disease & 5 & \multirow{2}{*}{1.10} \\
\hline Hemoglobin SC disease & 1 & \\
\hline Oncological disease & $\mathbf{6}$ & \\
\cline { 1 - 2 } Uterine cervical neoplasms & 3 & \\
\hline Multiple myeloma & 3 & \\
\hline
\end{tabular}

Table 2: Distribution of patients according to the history of the 542 patients admitted in first nephrology consultation.

The physical examination revealed a hypertension in $70.1 \%$ of the cases, a edema in $21.2 \%$ of which $13.0 \%(\mathrm{n}=15 / 115)$ were in the anasarca state. Hypertension was grade I in $21.8 \%(\mathrm{n}=118)$, grade II in $24.5 \%(\mathrm{n}=124)$ and grade III in $24.9 \%(\mathrm{n}=135)$ of the cases. Urine strip was used in $18(3.32 \%)$ patients, were negative in 2 patients, revealed proteinuria (PU) in 13 patients, hematuria $(\mathrm{HU})$ in 8 patients, leukocyturia in 6 patients, and nitrites in 2 patients. Hypovolemia was noted in 17 patients (3.13\%). The uremic syndrome was noted in 195 patients or $35.97 \%$ of the cases and was chronic in 193 patients.

Serum creatinine was measured in 518 patients or $95.75 \%$ of cases. Its mean was $45.81+/-1.51 \mathrm{mg} / \mathrm{l}$. The distribution of patients with respect to the serum creatinine level is shown in (Figure 2). The mean GFR was $42.33+/-35.22 \mathrm{ml} / \mathrm{min} / 1.73 \mathrm{~m} 2$. The mean hemoglobin level was $10.76+/-4.45 \mathrm{~g} / \mathrm{dl}$, and anemia was observed in $69.60 \%(300 / 431)$ of the patients and in $77.80 \%$ of patients with GFR below $60 \mathrm{ml} / \mathrm{min} / 1.73 \mathrm{~m} 2$. It was normochromic normocytic in $70.95 \%$. One hundred and ninety-eight (198) patients or $45.20 \%$ had a macroproteinuria while 107 or $24.42 \%$ had a microalbuminuria. PU was nephrotic in $19.45 \%$ of cases. HU was noted at $29.41 \%$ and leukocyturia at $26.96 \%$ of the patients. Other biological parameters are shown in (Table 3 ).

Kidney ultrasound was performed in 423 patients and $32.38 \%$ were found to have small kidneys and poor differentiation.

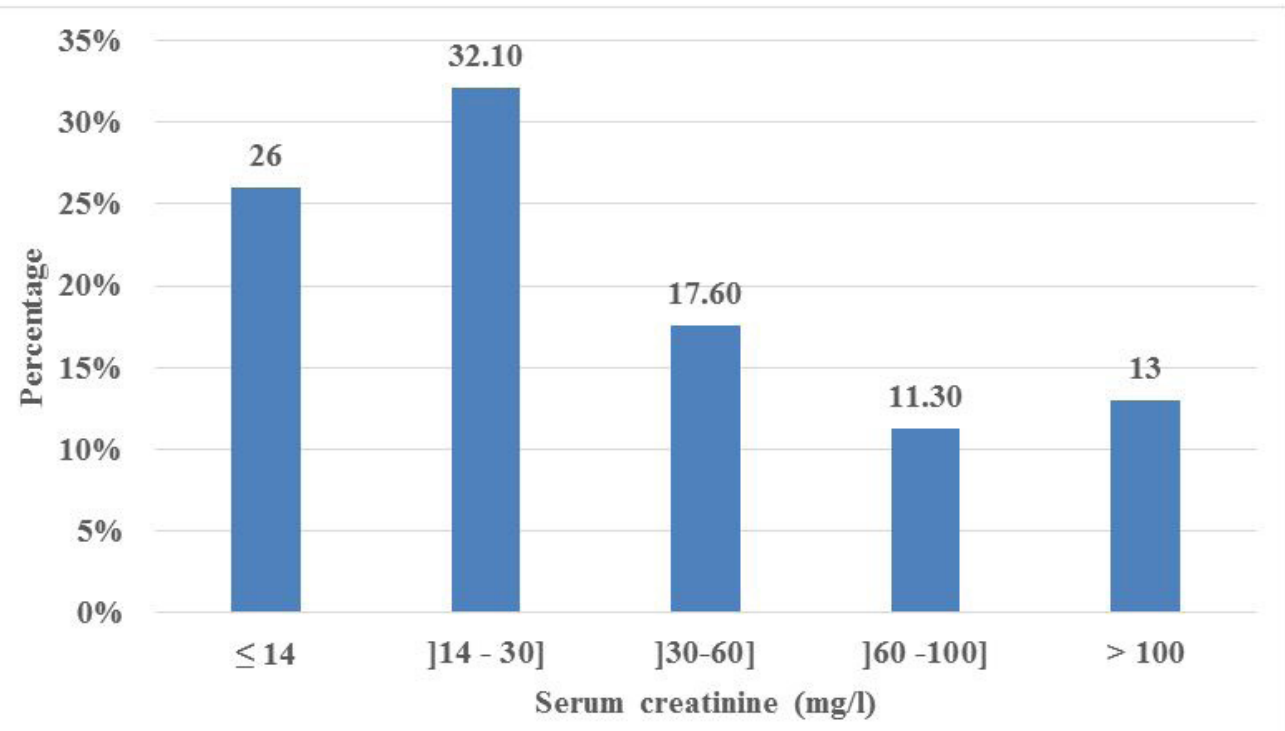

Figure 2: Distribution of 518 patients admitted in first nephrology consultation according to serum creatinine

\begin{tabular}{|c|c|c|}
\hline Biological parameters & Mean $+/$ - standard deviation & Number of consultants who benefited from the dosage \\
\hline Serum creatinin $(\mathbf{m g} / \mathbf{l})$ & $45.81+/-1.51$ & 518 \\
\hline Blood urea nitrogen $(\mathrm{g} / \mathbf{l})$ & $0.94+/-0.82$ & 518 \\
\hline eGFR $\left(\mathbf{m l} / \mathbf{m i n} / \mathbf{1 . 7 3 \mathbf { m } ^ { 2 } )}\right.$ & $42.33+/-35.22$ & 518 \\
\hline Hemoglobin $(\mathbf{g} / \mathbf{d l})$ & $10.76+/-4.45$ & 431 \\
\hline Serum uric $(\mathbf{m g} / \mathbf{l})$ & $76.54+/-22.90$ & 75 \\
\hline Blood sugar $(\mathbf{g} / \mathbf{l})$ & $1.14+/-0.49$ & 266 \\
\hline Proteinuria $(\mathbf{g} / \mathbf{2 4 h})$ & $0.92+/-1.28$ & 438 \\
\hline
\end{tabular}

Table 3: Mean, standard deviation of biological parameters and number of patients who benefit from the dosage in patients admitted in fist nephrology consultation during the study period.

Electrocardiogram was performed in 180 patients and pathological in 146 patients or $81.11 \%$ of cases. The researcher recorded sinus rhythm in 168 (93.33\%) patients, left ventricular hypertrophy (LVH) in 105 (48.16\%) patients, and left atrial hypertrophy 
(LAH) in $47(21.15 \%)$ patients. Cardiac ultrasonography was performed in 68 patients and was found to be abnormal in 50 patients $(73.52 \%)$. The researcher had found an LVH in $16.94 \%$, pulmonary hypertension in $9.32 \%$, segmental kinetic disorders in $3.38 \%$ and heart failure in $9.32 \%$ of the patients.

The first consultation diagnosed acute kidney injury in $7.74 \%$ of patients, chronic renal failure in $64.02 \%$ of patients, and CKD stage 1 or 2 in $19.37 \%$ of patients. The age of the CKD patients was over 60 in $47.99 \%$ of the cases. The distribution of patients according to the stage of the MRC is shown in (Figure 3).

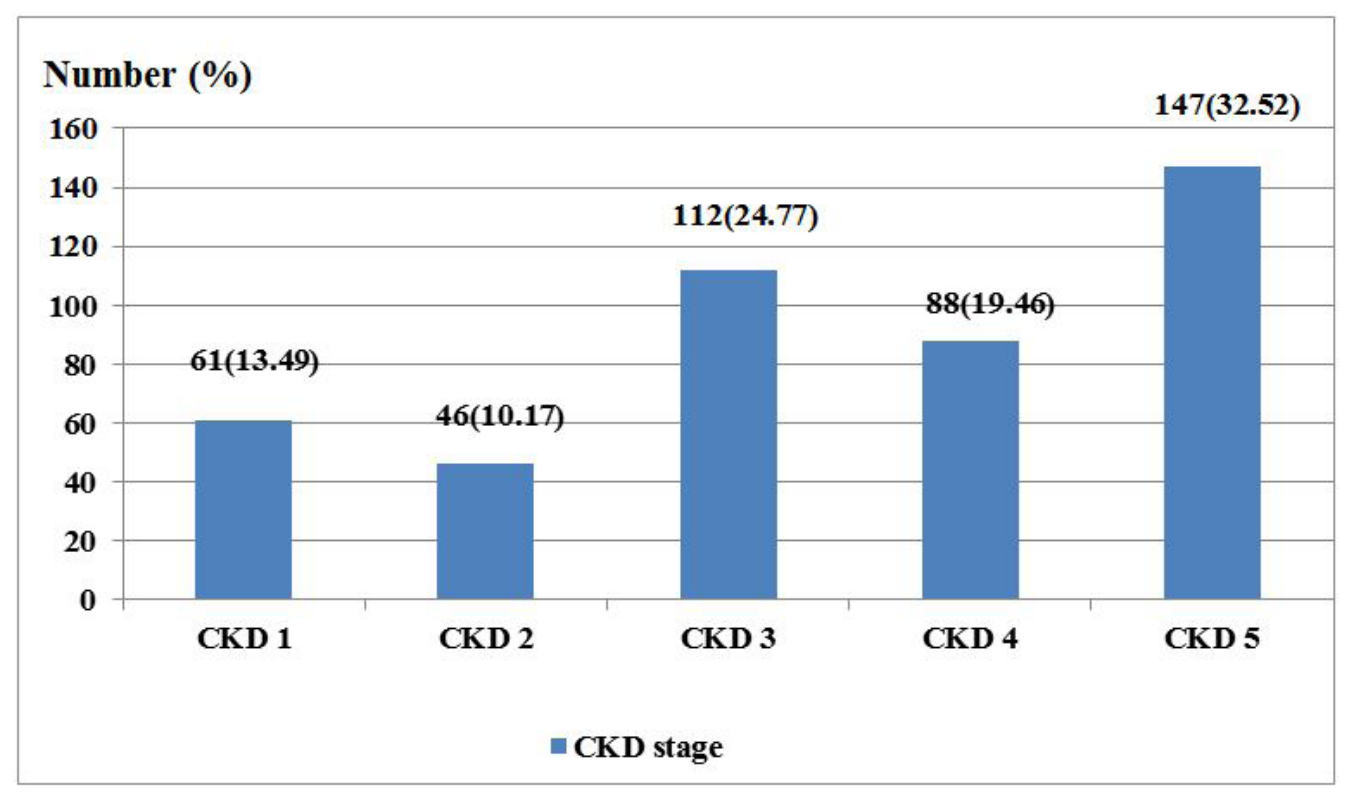

Figure 3: Distribution of 452 CKD patients admitted in first nephrology consultation according to the stage of CKD

\section{Discussion}

During the study period, our department admitted 542 new outpatient cases. This high incidence can be explained by the fact that the nephrology department of ALD-UHC is the largest national reference nephrology service.

The mean age of patients was $53 \pm 16$ years. This result is consistent with that observed in developing countries, with an average age of $52 \pm 18$ years in Morocco and $51 \pm 18$ years in Togo [8,9]. Coulibaly et al. reported an increase in the age of patients at the first nephrology consultation in Burkina Faso with a mean age of 40 years in 1998 to 45 years in 2013 [10]. The young age of the patients admitted for their first nephrology consultation reflects the young age of the Senegalese population. Several scholars report a predominance of men at the first consultation [5,9-11]. In fact, renal diseases are more common in men [12]. The majority of patients were referred by general practitioners followed by cardiologists and urologists. This result is consistent with the literature $[8-10,13]$. Cardiologists work very often with nephrologists in cardio-renal syndromes including type 1 , type 2, and type 5. Alteration of renal function was found to be the main reason for consultation in nephrology. This result is consistent with the literature data [8-10,13-15]. The majority of patients were admitted at stages 4 or 5 of the CKD. This is due to the asymptomatic nature of $\mathrm{CKD}$, the lack of awareness of the populations and general practitioners, and the poor performance of health systems with poorly defined courses of care for cases of renal failure. Routine screening of at-risk individuals will allow early discovery of CKD and better management. The urine strip was only used in 17 patients, i.e., 3.36\% of them. This is in contrast with the Swedish study which reported that the urine strip was the most commonly used screening tool for proteinuria in patients with a $24 \%$ rate [16].

In our study, patients were seen for the first time with a mean GFR of $42.33+/-35.22 \mathrm{ml} / \mathrm{min} / 1.73 \mathrm{~m} 2$. A lower GFR was noted during the first consultation in Canada $(29+/-22 \mathrm{ml} / \mathrm{min} / 1.73 \mathrm{~m} 2)$ [3]. The majority of patients were admitted in the advanced stage of CKD. This shows a delay in referral of patients to nephrologists. This problem was highlighted in several studies in different parts of the world: The United States, Australia, Europe and sub-Saharan Africa [12,17-22]. These results show that the delay in the management of chronic renal failure is not limited to underdeveloped countries. This result is quite alarming as the later the diagnosis, the worse the CKD prognosis. The adverse consequences of late management in nephrology are numerous and well-known: more precarious clinical state and more marked biological abnormalities when considering renal replacement therapy, longer hospital stay, and increased mortality rate both short- and long-term $[17,19,21,23]$. Thus, public awareness policies and practitioners must be employed to promote early diagnosis of CKD in Senegal. In our study, PU was sought in $80.81 \%$ of the patients. PU dosing was not as common in the other studies. In fact, it was performed in $30 \%$ of patients in the Curtis cohort and $22.9 \%$ of patients in the Prevot et al. cohort [3,13]. Gasparini et al. had noted a poor evaluation of PU even in patients at risk (diabetic, hypertensive) [16]. PU, independent of GFR, is a major risk factor for poor renal prognosis and mortality [24]. PU was pathological in $69.63 \%$ of our patients who received a dosage. This figure was higher than that recorded in France (29.9\%) [13]. 
The etiological research of the kidney disease is the most difficult step of the diagnostic approach in our regions because majority of the patients are seen at an advanced stage of CKD making it difficult to acquire the renal biopsy. This difficulty could largely explain the high rate of undetermined causes of CKD. Indeed, no cause could be determined in $20.45 \%$ of the cases of our study. In the literature, this figure varies between $27.1 \%$ and $62 \%$ [23,25]. In most African studies such as ours, the known causes are by far dominated by hypertension followed by diabetic nephropathy with rates varying between $25 \%$ and $62.1 \%$ for hypertension and between $11 \%$ and $20.6 \%$ for diabetic nephropathy $[10,15,26]$. In western countries, the leading cause of CKD is also hypertension followed by diabetes [12,27].

Our study has several limitations; it is a monocentric retrospective study, several biological parameters were not collected and some records were not exploitable. A cross-sectional and at best prospective multi-center study is necessary to better characterize the first nephrological consultation and to be able to extrapolate the results at the national level.

\section{Conclusion}

Patients referred for nephrology consultation are often seen at an advanced stage of CKD. In this study, impaired renal function was the primary reason for consultation and the majority of patients were admitted at stages 4 or 5 of CKD. This delayed diagnosis is associated with an increase in morbidity and mortality factors and the consequent poor prognosis and also with an increase in the cost of health. Thus, programs for the early detection and prevention of kidney diseases should be instituted especially for atrisk individuals.

\section{References}

1. Levey AS, Coresh J, Balk E, Kausz AT, Levin A, et al. (2003) National Kidney Foundation practice guidelines for chronic kidney disease: evaluation, classification and stratification. Ann Intern Med 139: 137-47.

2. Hill NR, Fatoba ST, Oke JL, Hirst JA, O'Callaghan CA, et al. (2016) Global prevalence of chronic kidney disease - a systematic review and meta-analysis. PLoS One 11: e0158765.

3. Curtis BM, Barett BJ, Djurdjev O, Singer J, Levin A (2007) Evaluation and treatment of CKD patients before and at their first nephrologists encounter in Canada. Am J Kidney Dis 50: 733-42.

4. Sumaili EK, Krzesinski JM, Cohen EP, Nazaire MN (2010) Epidémiologie de la maladie rénale chronique en République démocratique du Congo:une revue synthétique des études de Kinshasa, la capitale. Nephrol Ther 6: 232-9.

5. WHO (1999) World health organization-International society of hypertension guidelines for the management of hypertension. Guidelines subcommittee. J Hypertens 17: 151-83.

6. Levey AS, Bosch JP, Lewis JB, Greene T, Rogers N, et al. (1999) A more accurate method to estimate glomerular filtration rate from serum creatinine: a new prediction equation. Modification of Diet in Renal Disease Study Group. Ann Intern Med 130: 461-70.

7. Alberti KG, Zimmet PZ (1998) Definition, diagnosis and classification of diabetes mellitus and its complications. Part 1: diagnosis and classification of diabetes mellitus provisional report of a WHO consultation. Diabet Med 15: 539-53.

8. Mbarki H, Youbi REl, Maaroufi C, Benzakour K, Batta FZ, et al. (2009) Profil épidémiologique des patients en première consultation de néphrologie. Rev Epidemio Sante Pub 57: S41.

9. Sabi KA, Noto-Kadou-Kaza B, Amekoudi YE, Tsevi MC, Kossidze K, et al. (2014) Profil épidémio-clinique des patients en primo-consultation néphrologique au Togo. Médecine Santé Trop 24: 169-71.

10. Coulibaly G, Guissou C, Lengani A (2011) Primo-consultation néphrologique au Centre Hospitalier Universitaire Yalgado Ouedraogo de Ouagadougou (Burkina Faso). Nephrol Ther 7: 369.

11. Halle MP, Kengne AP, Ashuntantang G (2009) Referral of patients with kidney impairment for specialist care in a developing country of sub-Saharan Africa. Ren Fail 31: 341-8.

12. Kaze FF, Halle MP, Mopa HT, Ashuntantang G, Fouda H, et al. (2015) Prevalence and risk factors of chronic kidney disease in urban adult Cameroonians according to three common estimators of the glomerular filtration rate: a cross-sectional study. BMC Nephrol 16: 96.

13. Prevot J, Bayat S, Vigneau C (2016) Motifs de primo-consultations en néphrologie dans le territoire de santé de Rennes en 2014 . Nephrol Ther 12: 381.

14. Cordonnier Ch, Couchoud C (2002) Evaluation de la qualité de la prise en charge des nouveaux patients en insuffisance rénale à la Réunion. Néphrologie 23: 29-34.

15. van Rensburg BW, van Staden AM, Rossouw GJ, Joubert G (2010) The profile of adult nephrology patients admitted to the Renal Unit of the Universitas Tertiary Hospital in Bloemfontein, South Africa from 1997 to 2006. Nephrol Dial Transplant 25: 820-4.

16. Gasparini A, Evans M, Coresh J, Grams ME, Norin O, et al. (2016) Prevalence and recognition of chronic kidney disease in Stockholm healthcare. Nephrol Dial Transplant 31: 2086-94.

17. Winkelmayer WC, Owen WF, Levin R, Avorn JA (2003) A propensity analysis of late versus early nephrologist referral and mortality on dialysis. J Am Soc Nephrol 14: 486-92.

18. Khan SS, Xue JL, Kazmi WH, Gilbertson DT, Obrador GT, et al. (2005) Does predialysis nephrology care influence patient survival after initiation of dialysis?. Kidney Int 67: 1038-46.

19. Stack AG (2003) Impact of timing of nephrology referral and pre-ESRD care on mortality risk among new ESRD patients in the United States. Am J Kidney Dis $41: 310-8$.

20. Cass A, Cunningham J, Snelling P, Ayanian JZ (2003) Late referral to a nephrologist reduces access to renal transplantation. Am J Kidney Dis 42: 1043-9.

21. Kessler M, Frimat L, Panescu V, Briançon S (2003) Impact of nephrology referral on early and midterm outcomes in ESRD: EPidemiologie de l'Insuffisance Rénale chronique terminale en Lorraine (EPIREL): results of a 2-year, prospective, community-based study. Am J Kidney Dis 42 : $474-85$. 
22. Gorriz JL, Sancho A, Pallardo LM, Amoedo ML, Barril G, et al. (2002) Longer pre-dialysis nephrological care is associated with improved long-term survival of dialysis patients. Nephrol Dial Transplant 17: 1354-5

23. Black C, Sharma P, Scotland G, McCullough K, McGurn D, et al. (2010) Health Technol Assess 14: 1-184.

24. Schmieder RE, Manns BJ, Lioyd A, James MT, Klarenbach S, et al. (2010) Relation betwen kidney function, proteinuria, and adverse outcomes. JAMA 303: 423-9.

25. Ouattara B, Ouffoue Kra, Hubert Yao, Kouamé Kadjo, Ezani Kodjo Niamkey (2011) Particularités de l'insuffisance rénale chronique chez des patients adultes noirs hospitalisés dans le service de médecine interne du CHU de Treichville. Nephrol Ther 7: 531-4.

26. Naicker S (2010) Challenges for nephrology practice in sub-saharan Africa. Nephrol Dial Transplant 25: 649-50.

27. Daugas E, Dussol B, Henri P, Joly D, Juillard L, et al. (2012) PREPARE - étude transversale observationnelle sur la prise en charge de l'insuffisance rénale chronique en néphrologie avant le stade d'épuration extrarénale en France. Nephrol Ther 8: 439-50.

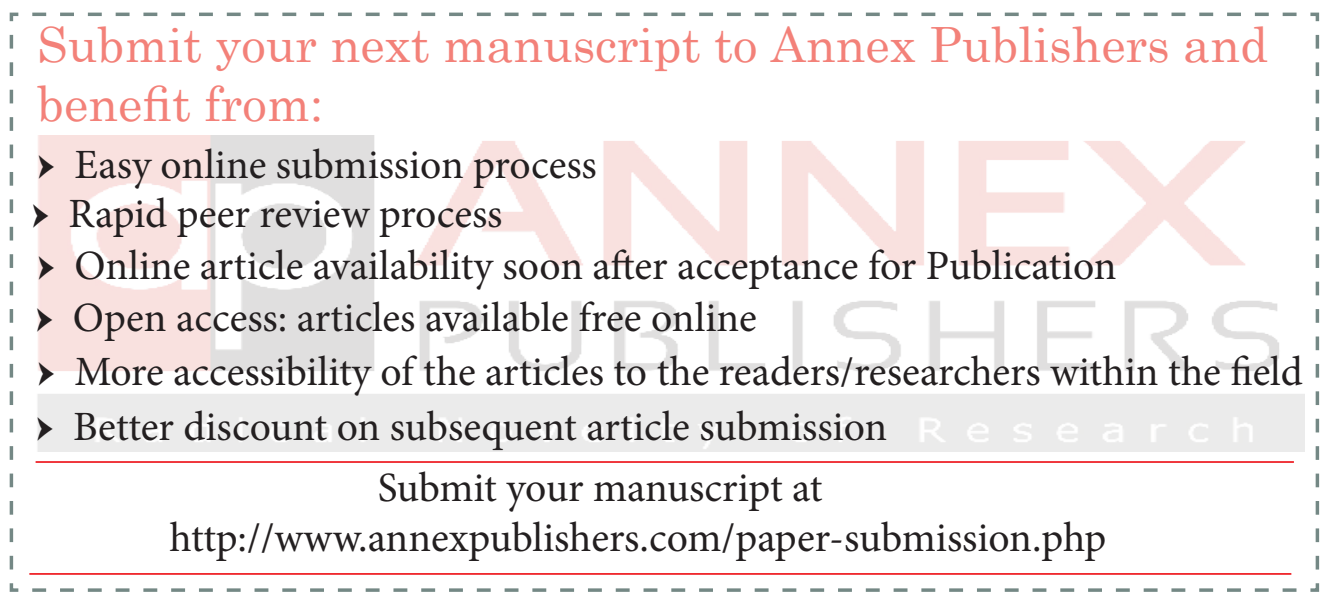

